\title{
Factors Affecting Exercise Test Performance in Patients After Liver Transplantation
}

\author{
Katarzyna Kotarska, ${ }^{1}$ Ewa Wunsch, ${ }^{2}$ Lukasz Jodko, ${ }^{3}$ Joanna Raszeja-Wyszomirska, ${ }^{4}$ Izabela Bania, ${ }^{3}$ \\ Malgorzata Lawniczak, ${ }^{5}$ Dimitrios Bogdanos, ${ }^{6}$ Zdzislawa Kornacewicz-Jach, ${ }^{3}$ and Piotr Milkiewicz ${ }^{2,4,}{ }^{*}$ \\ ${ }^{1}$ Department of Physical Culture and Health Promotion, University of Szczecin, Szczecin, Poland \\ ${ }^{2}$ Department of Clinical and Molecular Biochemistry, Pomeranian Medical University, Szczecin, Poland \\ ${ }^{3}$ Department of Cardiology, Pomeranian Medical University, Szczecin, Poland \\ ${ }^{4}$ Hepatology and Internal Medicine Unit, Department of General, Transplant and Liver Surgery, Medical University of Warsaw, Warsaw, Poland \\ ${ }^{5}$ Department of Gastroenterology, Pomeranian Medical University, Szczecin, Poland \\ ${ }^{6}$ Institute of Liver Studies, School of Medicine, King's College Hospital, London, UK \\ "Corresponding author: Piotr Milkiewicz, Hepatology and Internal Medicine Unit, Department of General, Transplant and Liver Surgery, Medical University of Warsaw, Warsaw, \\ Poland. Tel: +48-225991662, Fax: +48-225991663, E-mail: p.milkiewicz@wp.pl
}

Received 2015 December 01; Revised 2016 February 20; Accepted 2016 February 24.

\begin{abstract}
Background: Cardiovascular diseases are a leading cause of morbidity and mortality in solid organ transplant recipients. In addition, low physical activity is a risk factor for cardiac and cerebrovascular complications.

Objectives: This study examined potential relationships between physical activity, health-related quality of life(HRQoL), risk factors for cardiovascular disease, and an exercise test in liver-graft recipients.

Patients and Methods: A total of 107 participants (62 men/45 women) who had received a liver transplantation (LT) at least 6 months previously were evaluated. Physical activity was assessed using three different questionnaires, while HRQoL was assessed using the medical outcomes study short form (SF)-36 questionnaire, and health behaviors were evaluated using the health behavior inventory (HBI). The exercise test was performed in a standard manner.

Results: Seven participants (6.5\%) had a positive exercise test, and these individuals were older than those who had a negative exercise test $(\mathrm{P}=0.04)$. A significant association between a negative exercise test and a higher level of physical activity was shown by the Seven-day physical activity recall questionnaire. In addition, HRQoL was improved in various domains of the SF-36 in participants who had a negative exercise test. No correlations between physical activity, the exercise test and healthy behaviors, as assessed via the HBI were observed.

Conclusions: Exercise test performance was affected by lower quality of life and lower physical activity after LT. With the exception of hypertension, well known factors that affect the risk of coronary artery disease had no effect on the exercise test results.
\end{abstract}

Keywords: Physical Activity, Liver Transplantation, Exercise Test

\section{Background}

Liver transplantation (LT) is a life-saving procedure for individuals with end-stage liver disease, and improvements in surgical techniques, intensive care, and immunosuppressive regimens have resulted in significant improvements in short-term survival. Therefore, the focus has now shifted to address the long-term outcomes of LT. Organ transplantation is associated with several multifactorial metabolic complications that may depend on a variety of factors, including the function of the transplanted liver, the adverse effects of immunosuppression, organ complications induced by previous liver failure (e.g., hepatic cardiomyopathy), or concomitant diseases. Nonetheless, advances in LT allow the treatment of older and higher risk individuals, providing good outcomes. Unfortunately, excessive weight gain, hypertension, hyperlipidemia, and diabetes mellitus, also related to immunosuppressive regimens, are observed in transplant recipients. In addition to a sedentary lifestyle, levels of fitness and strength that are $40 \%$ to $50 \%$ below the age-expected values (1), a low level of physical activity, and components of the metabolic syndrome are all risk factors for major vascular complications. Liver transplant recipients with a low level of physical activity are also more likely to suffer from cardiopulmonary complications $(2,3)$. Cardiovascular complications after LT are the leading cause of non-transplant-related deaths (4). Thus, screening of asymptomatic individuals for underlying cardiac disease is an essential step in the evaluation of transplant recipients. The objective measures of exercise capacity (i.e., maximal oxygen uptake, $\mathrm{VO}_{2}$ peak, and quadriceps muscle strength) are low at 1 year after LT, and remain at reduced levels 2.5 years post-LT-significantly be- 
low age-predicted values (5). The exercise test is a common diagnostic tool for the detection of coronary artery disease (CAD), and coronary reserve and physical capacity in people diagnosed with CAD, as well as for monitoring treatment. It is useful in the prediction of the risk of major cardiovascular events, and is performed on a bicycle ergometer or a treadmill. The test involves a gradual increase in exercise intensity up to the level determined before the test or until the appearance of symptoms, at which point the exercise ceases. A stress test is stopped after the maximum heart rate predicted for a given age group is reached, or the onset of certain symptoms, or the appearance of electrocardiogram (ECG) changes. The test result is provided in a descriptive form, sometimes with accompanying charts (the electrical activity of the heart in a given time), and the procedure usually lasts from several to 12 minutes.

With improvements in LT procedures, health-related quality of life (HRQoL) and physical activity have become significant outcome parameters and an important focus of healthcare. HRQoL is a quantitative estimation of an individual's self-assessment of physical, functional, social, and psychological dimensions of life (6). Some socioeconomic and demographic differences in the short- and long-term HRQoL outcomes of LT recipients have been identified (7), and an improved quality of life has been observed in people who have been physically active following LT (8). Physical activity and employment could be associated with the degree of functional recovery, positively influencing both physical and mental aspects of HRQoL (9).

\section{Objectives}

This study examined potential relationships between self-reported assessment of physical activity, HRQoL, and risk factors for CAD, and the results of an exercise test in a well-defined group of people who underwent LT.

\section{Partients and Methods}

\subsection{Study Participants}

A total of 107 (62 men/45 women) consecutive liver transplant recipients reviewed between June 2011 and October 2012 in the outpatient clinic of M. Curie hospital in Szczecin, Poland, were included. The participants were divided into three groups, according to the time that had passed since LT, as follows: 6 - 12 months (group A, $\mathrm{n}=21$ ); 13 - 36 months (group $B, n=48$ ), and longer than 37 months (group $\mathrm{C}, \mathrm{n}=38$ ). Indications for LT included the following etiologies: alcoholic $(\mathrm{n}=24)$, chronic cholestatic liver diseases (i.e., primary biliary cirrhosis, primary sclerosing cholangitis, $n=23)$, and viral $(n=15)$, autoimmune hepatitis $(n=10)$, and other causes $(n=35)$. The mean body mass index (BMI) was $27.0 \pm 5.0 \mathrm{~kg} / \mathrm{m}^{2}$. Of the participants, 38 (35.5\%) were overweight (BMI between 25 and $30 \mathrm{~kg} / \mathrm{m}^{2}$ ) and $23(21.5 \%)$ were obese (BMI $\left.\geq 30 \mathrm{~kg} / \mathrm{m}^{2}\right)$. A total of 40 participants (37.4\%) were employed at the time of the survey. Among the 67 participants who were not working, 21 (31.3\%) were retired and 46 (68.7\%) were disability pensioners. The participants in work were younger than those who were unemployed ( $46 \pm 12.8$ vs $53 \pm 9.8$ years, $\mathrm{P}=0.003$ ), but they did not differ in terms of gender, or the amount of time that had passed since LT (data not shown). The participants' demographic and clinical data are summarized in Table 1.

Table 1. Participants' Demographic and Clinical Data

\begin{tabular}{|c|c|}
\hline Demographic Information & Values \\
\hline Total number of participants & 107 \\
\hline Age at transplantation, $y$ & $46.8 \pm 11.6$ \\
\hline \multicolumn{2}{|l|}{ mean $\pm S D$} \\
\hline range & $17-63$ \\
\hline Age at survey, $y$ & $49.9 \pm 11.4$ \\
\hline \multicolumn{2}{|l|}{ mean $\pm S D$} \\
\hline range & $21-67$ \\
\hline \multicolumn{2}{|l|}{ Gender, No. (\%) } \\
\hline Male & $62(57.9)$ \\
\hline Female & $45(42.1)$ \\
\hline \multicolumn{2}{|l|}{ BMI, $\mathrm{kg} / \mathrm{m}^{2}$} \\
\hline mean $\pm S D$ & $27.0 \pm 5.0$ \\
\hline range & $18.0-43.0$ \\
\hline \multicolumn{2}{|c|}{ Period after transplantation, mo, No. (\%) } \\
\hline Group A 6 - 12 & $21(19.6)$ \\
\hline Group B 13 - 36 & $48(44.9)$ \\
\hline Group C > 36 & $38(35.5)$ \\
\hline \multicolumn{2}{|l|}{ Employment } \\
\hline Yes & $40(37.4)$ \\
\hline No & $67(62.6)$ \\
\hline \multicolumn{2}{|l|}{ Original diagnosis } \\
\hline Alcoholic & $24(22.4)$ \\
\hline Cholestatic (PBC, PSC) & $23(21.5)$ \\
\hline Viral & $15(14.0)$ \\
\hline Autoimmune hepatitis & $10(9.4)$ \\
\hline Other & $35(32.7)$ \\
\hline
\end{tabular}




\subsection{Exercise Test}

We used a treadmill stress test, involving a gradual increase in the speed and angle to resemble an accelerating march on an increasingly steep hill. The test was performed according to the Bruce protocol, whereby the speed of the treadmill and its slope increased every $3 \mathrm{~min}$ utes. Exercise intensity was measured in metabolic equivalent of task (MET) (10). The stress test was interrupted after reaching the planned heart rate, or by accounting for clinical and ECG criteria. The most important clinical criterion was the occurrence of chest pain, while the electrocardiographic symptom of equal importance was a significant decrease in ST. Fatigue, dyspnea, increased heart rate, changes in blood pressure, intermittent claudication, and exercise load at which symptoms appeared were also important, as were arrhythmias and conduction disorders observed via ECG. Prior to the test, we carried out a detailed survey regarding symptoms, previous exercise tolerance, physical activity, comorbidities, and pharmacological treatment (10). We also collected anthropometric data, such as gender, age, height, and weight, which were useful in further analysis and stratification of risk to the participants. The test was always performed in the presence of a physician in a room equipped with an emergency kit, due to the possibility of serious complications (9). The test is currently most frequently used to estimate prognosis and to determine functional capacity, likelihood, and extent of coronary disease $(11,12)$.

\subsection{Assessment of Physical Activity}

Physical activity was assessed using the Polish version of the international physical activity questionnaire (IPAQ)long version (13). The IPAQ is an instrument for monitoring levels of physical activity of a population aged between 15 and 69 years, and was developed for surveillance activities and to guide policy development related to healthenhancing physical activity across various life domains. The long version of the IPAQ consists of 27 items and investigates four domains of physical activity (work, leisure, chores, and transport), as well as time spent sitting as a proxy for the sedentary behavior (4). Physical activity is reported as a continuous score, by intensity of physical activity (moderate or vigorous) or for walking, according to domain. Physical activity energy expenditure is calculated according to the following formula (in MET-min/week): number of days spent doing the activity $\times$ average duration of the activity per day $\times$ energy cost of the activity. The energy cost of an activity is expressed in MET, which is the ratio of energy expenditure during a given activity divided by resting energy expenditure. The following MET values were drawn from the scoring protocol: 3.3 for walking, 4 for moderate intensity physical activity, 8.0 for vigorous physical activity, 6.0 for cycling, 5.5 for vigorous physical activity in the garden or yard, and 3.0 for domestic activities (14). The seven-day physical activity recall questionnaire (PAR) is a semi-structured interview that estimates an individual's time spent in physical activity, strength, and flexibility activities for the 7 days prior to the interview. It encompasses a variety of physical activities, such as aerobic exercise, work-related activities, gardening, walking, recreation, and leisure-time physical activities. Only physical activities of at least moderate intensity are counted, and total kilocalories/day can be estimated from hours spent in physical activities of moderate, hard, and very hard intensity (5). The Minnesota leisure time physical activity questionnaire(MILTPAQ) collects information on free-time physical activity, providing the value of energy expenditure in kilocalories/week, and comprises a list of 63 sport, recreational, yard, and household activities. The participants are instructed to report whether or not they have performed each activity in the previous 12 months (5). In the present study, 105 (61 men/44 women) individuals completed the MILTPAQ.

\subsection{Assessment of Health-Related Quality of Life}

HRQoL was assessed using the medical outcomes study short form (SF-36), which is the most widely used and extensively validated generic questionnaire for the assessment of HRQoL in various clinical settings and different populations (15). It contains 36 items grouped in eight domains of physical health (physical functioning, role limitation-physical, bodily pain, and general health) and mental health (vitality, social functioning, role limitationemotional, mental health). Each domain is scored between 0 and 100 points, with higher scores indicating better HRQoL. Two summary scores, the physical component and the mental component, are obtained as a mean value calculated from appropriate domains. A license numbered CT132326/OP012559 was obtained for the use of the SF-36 questionnaire in this study.

\subsection{Assessment of Health Behavior}

The health behavior inventory (HBI) comprises 24 questions to evaluate health behavior in four domains: nutrition habits, preventive behavior, health practices, and mental attitude (16). Values selected by the tested individual are summed to obtain an overall intensity of health behavior, ranging from 24 to 120 points. The higher the score, the greater is the intensity of the declared behaviors. The overall rate is converted into standardized units and is subject to interpretation according to a scale of stens, as follows: 
- 1 - 4 stens: low score;

- 5 - 6 stens: moderate score;

- 7 - 10 stens: high score (17).

\subsection{Statistical Analysis}

Data are shown as means and standard deviations and were analyzed using Stat-View-5 software (SAS institute, Cary, NC, US). Correlations were tested using the Pearson correlation test. $\mathrm{P}<0.05$ was considered statistically significant.

\subsection{Ethics}

Written informed consent was obtained from each study participant. The study protocol was approved by the appropriate ethics committee of pomeranian medical university (KB -0012/51/11 dated 08.06.2011) and conforms to the ethical guidelines of the 1975 Declaration of Helsinki (6th revision, 2008).

\section{Results}

\subsection{Exercise Test}

All 107 ( 62 men/45 women) participants underwent the exercise test, and 92 (86\%) tested negative, seven (6.5\%) tested positive, and eight (7.5\%) had a non-diagnostic result. The reasons for the non-diagnostic results were low exercise tolerance and tiredness. Participants who tested positive were older at LT and in the exercise test than those with a negative test result ( $56 \pm 6.3$ vs $46 \pm 1.2$ years, $\mathrm{P}=$ 0.025 and $58 \pm 6.2$ vs $49 \pm 11.6$ years, $\mathrm{P}=0.04$, respectively). A significant association between the exercise test and hypertension was found $\left(\chi^{2}=9.67 ; \mathrm{P}=0.01\right)$, while no association between diabetes, hypercholesterolemia, cigarette smoking, and exercise test was observed (Table 2).

\subsection{Physical Activity}

The PAR questionnaire showed that participants with a negative test were more physically active than those with a positive test, with regard to both daily (105.3 \pm 12.4 vs 95.3 \pm 9.9 kilocalories $/ \mathrm{kg} /$ day, $\mathrm{P}=0.039$ ) and weekly physical activity (736.8 \pm 86.8 vs $665.7 \pm 69.4$ kilocalories/kg/week, $\mathrm{P}$ $=0.036$ ) (Table 3 ). The IPAQ showed that a significant proportion of participants with a non-diagnostic exercise test had higher scores in the sitting time domain, compared to those with both positive and negative results ( $810 \pm 106.4$ vs. $548.6 \pm 87.8$ MET-min/week, $\mathrm{P}=0.004 ; 810 \pm 106.4$ vs $624.6 \pm 183.1$ MET-min/week, $\mathrm{P}=0.004)$. Participants who failed to complete the exercise test were usually less accustomed to regular exercise and experienced fatigue earlier than the other participants (Table 3). With regard to MILTPAQ, participants with a negative exercise test showed higher physical activity in comparison to those who tested positively, but this difference was not statistically significant (1337.9 \pm 1621 vs $686.5 \pm 633.41$ total activity kilocalories/week, $\mathrm{P}=0.287$ ).

\subsection{Quality of Life}

Analysis of the SF-36 questionnaire showed that participants who had a negative exercise test had a higher quality of life in various domains, including role limitationemotional (76.5 \pm 21.1 vs $53.6 \pm 17.3, \mathrm{P}=0.007)$, mental health (69.2 \pm 16.3 vs $53.6 \pm 19.9, \mathrm{P}=0.016)$, and mental component summary score $(47.2 \pm 9.2$ vs $38.7 \pm 11.9, \mathrm{P}=$ $0.019)$. In the domain of general health and vitality, the results were of borderline significance, confirming a trend toward higher quality of life in participants with better exercise tolerance (Table 4).

HBI analysis showed no significant correlations between the different domains of health behavior and the results of the cardiac test (Table 5).

\section{Discussion}

We assessed a variety of factors affecting the risk of cardiovascular complications in liver transplant recipients and searched for potential relationships between physical activity, HRQoL, and the results of an exercise test. We found that participants with a positive exercise test were older, and, with the exception of hypertension, the components of the metabolic syndrome did not affect the cardiac exercise test. Liver transplant recipients who tested negative for the exercise test were more physically active when assessed with the PAR questionnaire and had better results in various domains of the SF-36. A recently published meta-analysis of observational studies showed that the 10year risk of developing cardiovascular complications following LT was $13.6 \%$, which was $64 \%$ greater than that of the control group (18). In addition, Sprinzl et al. recently showed that de novo metabolic syndrome affected $32.9 \%$ of patients within 2 years of LT (19). The prevalence of metabolic syndrome following LT is significantly higher than that estimated for the general population, and posttransplant metabolic syndrome appears to be associated with an increased risk of major vascular events after LT (20). Kallwitz et al. (21) reported that metabolic syndrome is common following LT, with higher prevalence observed at least 1 year afterwards, and is inversely correlated with exercise intensity. Our own data also show an association between higher activity levels and lower BMI(22). However, the results of the present study did not confirm an association between hyperlipidemia or diabetes and the exercise test result. The same applies to the relationship be- 
Table 2. Relationship Between Selected Factors and Exercise Test

\begin{tabular}{|c|c|c|c|c|c|c|}
\hline & Negative Test (A, $n=92)$ & Positive Test $(B, \mathbf{n}=7)$ & Non-Diagnostic Test $(C, n=8)$ & $\mathbf{P}($ A vs. B $)$ & $\mathbf{P}($ A vs. C $)$ & P(B vs. C) \\
\hline Gender & & & & 0.263 & 0.263 & 0.263 \\
\hline Male & 55 & 2 & 5 & & & \\
\hline Female & 37 & 5 & 3 & & & \\
\hline $\operatorname{chi}^{2}$ & & & & 2.67 & 2.67 & 2.67 \\
\hline Age at transplantation & $45.8 \pm 1.2$ & $55.9 \pm 6.3$ & $51.3 \pm 3.2$ & 0.03 & 0.19 & 0.43 \\
\hline Age at survey & $49.0 \pm 11.6$ & $58.1 \pm 6.2$ & $53.3 \pm 3.2$ & 0.04 & - & - \\
\hline BMI, $\mathbf{k g} / \mathrm{m}^{2}$, mean $\pm \mathrm{SD}$ & $28.1 \pm 4.7$ & $25.9 \pm 4.7$ & $31.8 \pm 4.9$ & 0.24 & 0.002 & 0.15 \\
\hline Hypercholesterolemia & & & & 0.744 & 0.744 & 0.744 \\
\hline Yes & 18 & 2 & 2 & & & \\
\hline No & 60 & 4 & 4 & & & \\
\hline No data & 14 & 1 & 1 & & & \\
\hline $\operatorname{chi}^{2}$ & & & & 0.59 & 0.59 & 0.59 \\
\hline Diabetes type 2 & & & & 0.25 & 0.25 & 0.25 \\
\hline Yes & 22 & 3 & 3 & & & \\
\hline No & 61 & 3 & 3 & & & \\
\hline No data & 9 & 1 & 2 & & & \\
\hline $\operatorname{chi}^{2}$ & & & & 2.78 & 2.78 & 2.78 \\
\hline Hypertension & & & & 0.01 & 0.01 & 0.01 \\
\hline Yes & 18 & 4 & 3 & & & \\
\hline No & 60 & 2 & 1 & & & \\
\hline No data & 14 & 1 & 4 & & & \\
\hline $\operatorname{chi}^{2}$ & & & & 9.67 & 9.67 & 9.67 \\
\hline Smoking & & & & 0.370 & 0.370 & 0.370 \\
\hline Active & 33 & 5 & 5 & & & \\
\hline Previous & 12 & 0 & 0 & & & \\
\hline Never & 14 & 1 & 3 & & & \\
\hline No data & 33 & 1 & 0 & & & \\
\hline $\mathrm{chi}^{2}$ & & & & 4.27 & 4.27 & 4.27 \\
\hline
\end{tabular}

tween $\mathrm{HBI}$ and the exercise test result. A possible explanation for this somewhat surprising finding could be a significantly lower proportion of people with diabetes or dyslipidemia in our group when compared to the groups evaluated in other studies. Bianchi et al. reported that $32 \%$ of their study participants had diabetes, 51\% had dyslipidemia, and 53\% had arterial hypertension (23). Two other studies showed similar proportions - $41 \%$ and $61 \%$ with diabetes, and $45 \%$ and $62 \%$ with arterial hypertension (20, 24). In the present study, participants with self-reported higher physical activity were more likely to have a negative exercise test. These findings were statistically significant with regard to the PAR questionnaire and showed a clear trend in the IPAQ and the MILTPAQ. This corresponds with previously reported data showing that physical activity may reduce some comorbidities, especially cardiovascular risk factors (23). Physical activity appears to improve HRQoL by enhancing physical functioning in people compromised by poor health; transplant recipients show lower HRQoL scores than the general population (9). The majority of published studies have reported significantly improved HRQoL in liver transplant recipients compared to the pre-transplant period (24), while some have indicated that various physical symptoms may remain after transplantation (25). Weakness, limited range of motion, or pain may lead to reduced physical activity and gen- 
Table 3. Relationship Between Seven-Day Physical Activity Recall Questionnaire, IPAQ, and Exercise Test ${ }^{\mathrm{a}}$

\begin{tabular}{|c|c|c|c|c|c|c|c|}
\hline & & Negative Test $(\mathbf{n}=92)$ & Positive Test $(\mathbf{n}=7)$ & Non-Diagnostic Test $(n=8)$ & P(1 vs. 2) & $\mathbf{P}(\mathbf{1}$ vs. 3) & P(2 vs. 3$)$ \\
\hline \multicolumn{8}{|c|}{ Seven-Day Physical Activity Recall } \\
\hline & $\begin{array}{l}\text { Total physical activity per week, } \\
\text { absolute, Kcal/kg/week }\end{array}$ & $736.8 \pm 86.8$ & $665.7 \pm 69.4$ & $676.5 \pm 81.2$ & 0.036 & 0.058 & 0.807 \\
\hline & $\begin{array}{l}\text { Total physical activityper day, } \\
\text { absolute, Kcal/kg/day }\end{array}$ & $105.3 \pm 12.4$ & $95.3 \pm 9.9$ & $96.6 \pm 11.5$ & 0.039 & 0.056 & 0.832 \\
\hline & Total, MET-min/week & $4553.5 \pm 3557.2$ & $3789.4 \pm 2385.5$ & $4468.5 \pm 1622.9$ & 0.568 & 0.946 & 0.700 \\
\hline & Walking, MET-min/week & $1290.6 \pm 947.2$ & $1470.9 \pm 867.6$ & $1076.6 \pm 411.4$ & 0.616 & 0.527 & 0.407 \\
\hline & Moderate, MET-min/week & $2323.3 \pm 1280.3$ & $2318.6 \pm 2334.6$ & $3391.9 \pm 1516.4$ & 0.992 & 0.034 & 0.128 \\
\hline & Vigorous, MET-min/week & $939.6 \pm 3383.1$ & 0.000 & 0.000 & 0.450 & 0.422 & 0.000 \\
\hline & Sitting time, min/week & $624.6 \pm 183.1$ & $548.6 \pm 87.8$ & $810 \pm 106.4$ & 0.269 & 0.004 & 0.004 \\
\hline
\end{tabular}

${ }^{\mathrm{a}}$ Values are expressed as mean $\pm \mathrm{SD}$.

Table 4. Relationship Between SF-36 and Exercise Test ${ }^{\mathrm{a}}$

\begin{tabular}{|c|c|c|c|c|c|c|}
\hline SF-36 & Negative Test $(\mathbf{n}=92)$ & Positive Test $(\mathbf{n}=7)$ & Non-Diagnostic Test $(n=8)$ & P(1 vs. 2) & P(1 vs. 3) & P (2 vs. 3) \\
\hline PF & $74.2 \pm 21.8$ & $60 \pm 32$ & $61.2 \pm 29.2$ & 0.118 & 0.129 & 0.916 \\
\hline RP & $64.7 \pm 24.7$ & $60.7 \pm 14.3$ & $56.3 \pm 25.2$ & 0.672 & 0.344 & 0.722 \\
\hline BP & $72.6 \pm 27.8$ & $62.1 \pm 31.1$ & $66 \pm 29.5$ & 0.345 & 0.526 & 0.79 \\
\hline GH & $61.3 \pm 19.9$ & $48.4 \pm 10.7$ & $48.5 \pm 10.7$ & 0.089 & 0.073 & 0.994 \\
\hline VT & $62.4 \pm 17.4$ & $50 \pm 21$ & $55.5 \pm 13.5$ & 0.071 & 0.280 & 0.544 \\
\hline SF & $73.6 \pm 22.6$ & $71.4 \pm 24.7$ & $78.1 \pm 23.9$ & 0.804 & 0.594 & 0.571 \\
\hline RE & $76.5 \pm 21.1$ & $53.6 \pm 17.3$ & $70.8 \pm 28.2$ & 0.007 & 0.472 & 0.123 \\
\hline MH & $69.2 \pm 16.3$ & $53.6 \pm 19.9$ & $58.1 \pm 13.1$ & 0.016 & 0.068 & 0.590 \\
\hline PCS & $46.8 \pm 8.8$ & $44.6 \pm 7.8$ & $42.6 \pm 9.5$ & 0.522 & 0.204 & 0.673 \\
\hline MCS & $47.2 \pm 9.2$ & $38.7 \pm 11.9$ & $44.8 \pm 7.0$ & 0.019 & 0.475 & 0.203 \\
\hline
\end{tabular}

Abbreviations: BP, bodily pain; GH, general health; MCS, mental component summary; MH, mental health; PCS, physical component summary; PF, physical functioning; $\mathrm{RP}$, role limitation-physical; RE, role limitation-emotional; SF, social functioning; VT, vitality.

${ }^{\mathrm{a}}$ Values are expressed as mean $\pm \mathrm{SD}$.

Table 5. Relationship Between HBI and Exercise Test ${ }^{\mathrm{a}}$

\begin{tabular}{|c|c|c|c|c|c|c|}
\hline HBI & Negative Test $(\mathrm{n}=92)$ & Positive Test $(n=7)$ & Non-Diagnostic Test $(\mathrm{n}=\mathbf{8})$ & P(1 vs. 2) & P(1 vs. 3) & $P(2$ vs. 3) \\
\hline Health behaviors & $96.9 \pm 12.1$ & $102.3 \pm 9.9$ & $102.5 \pm 12.8$ & 0.260 & 0.213 & 0.972 \\
\hline Proper dietary habits & $3.8 \pm 0.7$ & $4.1 \pm 0.4$ & $3.7 \pm 0.9$ & 0.330 & 0.696 & 0.310 \\
\hline Preventive behaviors & $4.3 \pm 0.5$ & $4.6 \pm 0.4$ & $4.5 \pm 0.6$ & 0.128 & 0.215 & 0.785 \\
\hline Positive mental attitude & $4.1 \pm 0.6$ & $4.2 \pm 0.6$ & $4.5 \pm 0.6$ & 0.801 & 0.097 & 0.319 \\
\hline Health practices & $3.9 \pm 0.7$ & $4.1 \pm 0.5$ & $4.3 \pm 0.6$ & 0.418 & 0.114 & 0.606 \\
\hline Sten & $7.6 \pm 1.6$ & $8.1 \pm 1.3$ & $8 \pm 1.8$ & 0.421 & 0.537 & 0.865 \\
\hline
\end{tabular}

${ }^{\mathrm{a}}$ Values are expressed as mean $\pm \mathrm{SD}$.

eral fitness. Individuals who participate in regular physi- cal activity have significantly higher scores on all physical 
scales and the physical component summary score of the SF-36 (1). The regression model, which includes age, gender, time post transplantation, re-transplantation, recurrence of hepatitis $\mathrm{C}$, number of comorbid conditions, and physical activity participation, showed that both the number of comorbid conditions and participation in physical activity were significant independent contributors to the physical functioning scale and physical component summary score in the SF-36 measure. Painter et al. (26) indicated that physical activity is related to HRQoL after LT, independently of other coexisting medical conditions. They also previously reported that individuals who are physically active score above the general population norms for all physical scales of the SF-36, including vitality and social functioning (27), similar to the trend observed regarding general health and vitality in the present study. However, it must be emphasized that self-reported physical activity questionnaires (i.e., the IPAQ, MILTPAQ, and PAR) are subjective, and it is possible that respondents overestimate their physical activity. Objective measures, such as exercise tolerance and muscle strength, have been shown to improve after LT (28). However, even with these improvements, exercise tolerance and muscle strength remain significantly below age-predicted values and remain at these reduced levels at least 2.5 years post-LT (29). It has been suggested that this low level of functioning is related to physical inactivity following transplantation $(1,26,27)$. Indeed, as many as $50 \%-75 \%$ of LT recipients report being physically inactive $(1,26)$. Although quality of life improves considerably after LT, Kugler et al. found that transplant recipients showed the lowest HRQoL scores in the physical domain, 24 months after transplantation, when compared to kidney, heart, and lung recipients $(30,31)$. It has also been found that regular physical activity is significant in the long-term recovery process after LT and positively influences HRQoL (1). The results of our study showed that more physically active participants had higher scores in the mental domains of the SF-36, including role limitation - emotional, mental health, and mental component summary, which supports the hypothesis that increased physical activity may result in a reduction of depression and anxiety, and an increased ability to maintain independent living (32). Another study showed that physical activity improved mental functions in a majority of LT recipients (8). In summary, decreased HRQoL and lower physical activity exert a negative effect on exercise test results following LT. With the exception of hypertension, recognized factors related to the risk of CAD had no effect on exercise test results in the present study. The more physically active participants also reported a better HRQoL, primarily in the mental aspects. Therefore, LT recipients should be encouraged to exercise regularly to reduce their risk of cardiovascular morbidity.

\section{Acknowledgments}

Ewa Wunsch was supported by the foundation for Polish science and ministry of science and higher education of the Republic of Poland.

\section{Footnotes}

Authors' Contribution: Study concept and design: Katarzyna Kotarska, Joanna Raszeja-Wyszomirska, Zdzislawa Kornacewicz-Jach and Piotr Milkiewicz; acquisition of data: Katarzyna Kotarska, Joanna RaszejaWyszomirska, Lukasz Jodko and Izabela Bania; statistical analysis: Wunsch. Analysis and interpretation of data: Katarzyna Kotarska, Wunsch, Zdzislawa KornacewiczJach, Dimitrios Bogdanos and Piotr Milkiewicz; drafting of the manuscript: Katarzyna Kotarska, Wunsch, Piotr Milkiewicz and Dimitrios Bogdanos; critical revision of the manuscript for important intellectual content: Katarzyna Kotarska, Milkiewicz and Dimitrios Bogdanos; administrative, technical, and material suport: Katarzyna Kotarska and Zdzislawa Kornacewicz-Jach; study supervision: Piotr Milkiewicz, Zdzislawa Kornacewicz-Jach, Joanna Raszeja-Wyszomirska and Ławniczak; all authors edited and approved the final version of the manuscript.

Funding/Support: Ewa Wunsch was supported by the foundation for Polish science and the ministry of science and higher education of the Republic of Poland.

\section{References}

1. Painter P, Krasnoff J, Paul SM, Ascher NL. Physical activity and healthrelated quality of life in liver transplant recipients. Liver Transpl. 2001;7(3):213-9. doi: 10.1053/jlts.2001.22184. [PubMed: 11244162].

2. Sainz-Barriga M, Baccarani U, Scudeller L, Risaliti A, Toniutto PL, Costa MG, et al. Quality-of-life assessment before and after liver transplantation. Transplant Proc. 2005;37(6):2601-4. doi: 10.1016/j.transproceed.2005.06.045. [PubMed: 16182758].

3. Tanikella R, Kawut SM, Brown RJ, Krowka MJ, Reinen J, Dinasarapu $\mathrm{CR}$, et al. Health-related quality of life and survival in liver transplant candidates. Liver Transpl. 2010;16(2):238-45. doi: 10.1002/1t.21984. [PubMed: 20104497].

4. Pruthi J, Medkiff KA, Esrason KT, Donovan JA, Yoshida EM, Erb SR, et al. Analysis of causes of death in liver transplant recipients who survived more than 3 years. Liver Transpl. 2001;7(9):811-5. doi: 10.1053/jlts.2001.27084. [PubMed: 11552217].

5. Krasnoff JB, Vintro AQ, Ascher NL, Bass NM, Paul SM, Dodd MJ, et al. A randomized trial of exercise and dietary counseling after liver transplantation. Am J Transplant. 2006;6(8):1896-905. doi: 10.1111/j.16006143.2006.01391.x. [PubMed: 16889545].

6. Bownik H, Saab S. Health-related quality of life after liver transplantation for adult recipients. Liver Transpl. 2009;15 Suppl 2:S42-9. doi: 10.1002/lt.21911. [PubMed: 19876941]. 
7. Saab S, Bownik H, Ayoub N, Younossi Z, Durazo F, Han S, et al. Differences in health-related quality of life scores after orthotopic liver transplantation with respect to selected socioeconomic factors. Liver Transpl. 2011;17(5):580-90. doi: 10.1002/lt.22268. [PubMed: 21506246].

8. Rongies W, Stepniewska S, Lewandowska M, Smolis-Bak E, Dolecki W, Sierdzinski J, et al. Physical activity long-term after liver transplantation yields better quality of life. Ann Transplant. 2011;16(3):126-31. [PubMed: 21959520].

9. Masala D, Mannocci A, Unim B, Del Cimmuto A, Turchetta F, Gatto G, et al. Quality of life and physical activity in liver transplantation patients: results of a case-control study in Italy. Transplant Proc. 2012;44(5):1346-50. doi: 10.1016/j.transproceed.2012.01.123. [PubMed: 22664013].

10. Pruszczyk PHT, Drozdz J. . Warsaw: Medical Tribune Poland; 2009. Internal medicine - cardiology with the elements of angiology.

11. Braunwald E. Heart disease. Exercise stress testing. USA: Saunders; 1997.

12. Fox K, Garcia MA, Ardissino D, Buszman P, Camici PG, Crea F, et al. Guidelines on the management of stable angina pectoris: executive summary: The Task Force on the Management of Stable Angina Pectoris of the European Society of Cardiology. Eur Heart J. 2006;27(11):1341-81. doi: 10.1093/eurheartj/ehlo01. [PubMed: $16735367]$

13. Biernat ESR, Gajewski A. International Physical Activity Questionnaire (IPAQ). Phys Educ Sport. 2007;51:47-54.

14. IPAQ . Guidelines for data processing and analysis of the IPAQ 2013. Available from: http://www.ipaq.ki.se.

15. Ware JJ, Sherbourne CD. The MOS 36-item short-form health survey (SF-36). I. Conceptual framework and item selection. Med Care. 1992;30(6):473-83. [PubMed: 1593914].

16. Nowicki G. S. B., Kulik T. B., Goniewicz M. . Psychosocjsl factors and the pattern of type Abehavior and health behaviors in the prevenetion of cardiovascular risyk among adults. Polish J Cardiol. 2011;13(2):82-8.

17. Kawalec ERA, Porebska A. , Brzostek T. , Malinowska-Lipien I. . Health behaviours of obese and overweight patients. Nurs XXI Century. 2011;2(35):27-33.

18. Madhwal S, Atreja A, Albeldawi M, Lopez R, Post A, Costa MA. Is liver transplantation a risk factor for cardiovascular disease? A metaanalysis of observational studies. LiverTranspl. 2012;18(10):1140-6. doi: 10.1002/lt.23508. [PubMed: 22821899].

19. Sprinzl MF, Weinmann A, Lohse N, Tonissen H, Koch S, Schattenberg $\mathrm{J}$, et al. Metabolic syndrome and its association with fatty liver disease after orthotopic liver transplantation. Transpl Int. 2013;26(1):6774. doi: 10.1111/j.1432-2277.2012.01576.x. [PubMed: 23126674].

20. Laryea M, Watt KD, Molinari M, Walsh MJ, McAlister VC, Marotta PJ, et al. Metabolic syndrome in liver transplant recipients: prevalence and association with major vascular events. Liver Transpl. 2007;13(8):1109-
14. doi: 10.1002/lt.21126. [PubMed: 17663411].

21. Kallwitz ER, Loy V, Mettu P, Von Roenn N, Berkes J, Cotler SJ. Physical activity and metabolic syndrome in liver transplant recipients. Liver Transpl. 2013;19(10):1125-31. doi:10.1002/lt.23710. [PubMed: 23894084].

22. Kotarska K, Wunsch E, Kempinska-Podhorodecka A, RaszejaWyszomirska J, Bogdanos DP, Wojcicki M, et al. Factors affecting health-related quality of life and physical activity after liver transplantation for autoimmune and nonautoimmune liver diseases: a prospective, single centre study. J Immunol Res. 2014;2014:738297. doi: 10.1155/2014/738297. [PubMed: 24741621].

23. Bianchi G, Marchesini G, Marzocchi R, Pinna AD, Zoli M. Metabolic syndrome in liver transplantation: relation to etiology and immunosuppression. Liver Transpl. 2008;14(11):1648-54. doi: 10.1002/lt.21588. [PubMed: 18975273].

24. Albeldawi M, Aggarwal A, Madhwal S, Cywinski J, Lopez R, Eghtesad B, et al. Cumulative risk of cardiovascular events after orthotopic liver transplantation. Liver Transpl. 2012;18(3):370-5. doi: 10.1002/lt.22468. [PubMed: 22140067].

25. National Center for Biotechnology Information . Physical activity and cardiovascular health. NIH Consensus Development Panel on Physical Activity and Cardiovascular Health. JAMA. 1996;276(3):241-6. [PubMed: 8667571].

26. Painter PL, Luetkemeier MJ, Moore GE, Dibble SL, Green GA, Myll JO, et al. Health-related fitness and quality of life in organ transplant recipients. Transplantation. 1997;64(12):1795-800. [PubMed: 9422422].

27. Bravata DM, Olkin I, Barnato AE, Keeffe EB, Owens DK. Health-related quality of life after liver transplantation: a meta-analysis. Liver Transpl Surg. 1999;5(4):318-31. doi: 10.1002/lt.500050404. [PubMed: 10388505].

28. Hicks FD, Larson JL, Ferrans CE. Quality of Life after Liver Transplant. Res Nurs Health. 1992;15(2):111-9. doi:10.1002/nur.4770150205.

29. Bernard SL, Kincade JE, Konrad TR, Arcury TA, Rabiner DJ, Woomert A, et al. Predicting mortality from community surveys of older adults: the importance of self-rated functional ability. J Gerontol B Psychol Sci Soc Sci. 1997;52(3):S155-63. [PubMed: 9158572].

30. Kugler C, Gottlieb J, Warnecke G, Schwarz A, Weissenborn K, BargHock $\mathrm{H}$, et al. Health-related quality of life after solid organ transplantation: a prospective, multiorgan cohort study. Transplantation. 2013;96(3):316-23. doi: 10.1097/TP.0b013e31829853eb. [PubMed: 23715048].

31. Krasnoff JB, Vintro AQ, Ascher NL, Bass NM, Dodd MJ, Painter PL. Objective measures of health-related quality of life over 24 months postliver transplantation. Clin Transplant. 2005;19(1):1-9. doi:10.1111/j.13990012.2004.00306.x. [PubMed: 15659126].

32. Szark-Eckardt MKM, Cieslicka M. , Muszkieta R. , Prusik K. , Napierała M. . Cumulative risk of cardiovascular events after orthotopic liver transplantation. Open Med. 2015;10(1):209-15. 